\title{
Beta Actin Expression Profile in Malignant Human Glioma Tumors
}

\author{
Mohsen Ghezelbash', Nahid Masoudian', Mehdi Pooladi ${ }^{*}$ \\ 'Department of Biology, Damghan Branch, Islamic Azad university, Damghan, Iran \\ ${ }^{2}$ Department of Biology, School of Basic Sciences, Science and Research Branch, Islamic Azad University, Tehran, Iran
}

\begin{abstract}
Background: Proteomics is considered a new era in neurophysiological/ neuropathological research including brain tumors. Gliomas which are derived from glial cells are the most common type of brain tumor in humans.

Methods: In the present study the total protein content of healthy cells of the brain and brain tumor cells was extracted, purified and quantified by Bradford assay. Two-dimensional electrophoresis were used for protein separation followed by statistical analysis. Primary protein detection was performed based on the differences in isoelectric $\mathrm{pH}$, molecular weight of proteins and protein data banks, which was further confirmed by MALDI-TOF/TOF mass spectrometry (MS).

Results: Our results showed elevated levels of beta-actin protein expression in glioma brain tumor cells. It is important to know when a cell is transformed and when it becomes malignant. Here we evaluated the beta-actin expression in malignant cells.

Conclusion: Since structural changes are highly involved in tumor cell malignancy, beta-actin elevations can contribute in glioma tumor cell invasiveness.

Keywords: Beta-Actin; Glioma; Proteomics; Mass Spectrometry.
\end{abstract}

*Correspondence to

Mehdi Pooladi, Department of Biology, Damghan Branch, Islamic Azad university, Damghan, Iran. Tel: +98(917)3074007; Email: mehdi.pooladi7@gmail.com

\section{Published online 19 Junr} 2018

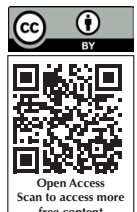

Citation: Ghezelbash M, Masoudian N, Pooladi M. Beta actin expression profile in malignant human glioma tumors. Int Clin Neurosci J. 2018;5(2):72-77. doi: 10.15171/icnj.2018.13.

\section{Introduction}

Cancer is defined as an abnormal growth and replication of cells, which interferes with normal physiology and function of the tissues and the body. ${ }^{1}$ Brain tumors are also a mass of unnecessary cells growing in the brain, which can be divided into two main groups. Primary brain tumors: tumors that originate from brain's tissues. Secondary brain tumors: which originate from other organs in the body and migrate to brain following metastasis. ${ }^{2-4}$

Primary brain tumors are classified as benign and malignant. Benign tumor cells have a slow proliferation rate, are rarely invasive with frequently normal microscopic phenotype. Malignant brain tumors on the other hand, are invasive with high proliferation rate and abnormal phenotype. Another classification by WHO consists of four tumor grades (I, II, III and IV)..$^{5-7}$

Glioma is the most common and most fatal type of primary brain tumors, which affects brain's hemispheres, but can also spread to brain parenchymal tissue. Glioma tumors are derived from glial cells and are sub-divided into astrocytoma, oligodendroglioma and oligoastrocytoma. ${ }^{8,9}$

Proteomics studies can be useful both in biological and clinical research, while one of its main applications is in tumor biology, which includes identifying possible protein biomarker candidates, diagnosis and treatment, pharmaceutics, protein complex analysis and drug target identification and studying the mechanism of action and possible side effects of anticancer drugs. Following genomics studies, proteomics also help obtain protein expression profiles by using two-dimensional electrophoresis (2DE), mass spectrometry (MS) and Bioinformatics tools. ${ }^{10-12}$

In the present study, used 2DE for separated proteins, MALDI-TOF/TOF for identified, and clustering and principal component analysis (PCA) for investigated the bata-actin expression change, is performed to obtain beta-actin protein expression profile in malignant human glioma tumor cells.

\section{Materials and Methods}

Twelve malignant human glioma tumor tissues were collected from excess tumor after surgical resection at hospital and tumors grade and malignancy was determined by the pathology department at the same hospital. Two normal tissue samples were also collected from the safe zone margin of tumor tissues. All collected samples were stored at $-80^{\circ} \mathrm{C}$.

(C) 2018 The Author(s). This is an open access article distributed under the terms of the Creative Commons Attribution License (http:// creativecommons.org/licenses/by/4.0/), which permits unrestricted use, distribution, and reproduction in any medium, provided the original work is properly cited. 


\section{Protein Extraction}

The following protocol was used for protein extraction and preparation from tumor tissue samples: tissue samples were washed by PBS, cell lysis by sonication (samples received 3 rounds of sonication and each round lasted 30 seconds), acetone (50\% and $100 \%)$ wash at $4^{\circ} \mathrm{C}, 15000 \mathrm{~g}$, and three rounds of 30 minutes each. In the following, the obtained pellet was kept on $-20^{\circ} \mathrm{C}$ overnight. Protein solubilization following acetone removal by adding $1 \mathrm{ml}$ of rehydration buffer and $50 \mu \mathrm{L}$ of protease inhibitor to each protein pellet containing tubes. Finally, the Bradford assay was used for analysis of each tissue samples protein content.

\section{Two-Dimensional Gel Electrophoresis}

Two-dimensional gel electrophoresis for protein separation was performed with IPG strips $(18 \mathrm{~cm})$ by isoelectric focusing (IEF). IPG trips were then transformed to SDS-PAGE gel and proteins were further separated based on their molecular weight. Followed by a final Coomassie blue staining of SDS-PAGE gel.

\section{SDS-PAGE Scan and Bioinformatics Analysis}

SDS-PAGE gels were scanned using scanner Densitometer GS-800 (BioRad) scanner at $600 \mathrm{dpi}$ in tagged image file format (TIFF). Image MasterTM 2D platinum v6. 0 software was then used to extract and digitize data from graphical images of scanned gels through detecting, normalizing, matching and comparing protein spots, according to their volume percent, followed by primary analysis of 2D images by Quantity One ${ }^{\circledR}$ software. The obtained scanned images of SDS-PAGE gels were further analyzed by Non-Linear Dynamics Progenesis Same Spot ${ }^{\circledR}$ software. After comparing the obtained 2D images with control samples, primary protein detection was performed based on the protein bands.
Mass Spectrometry Analysis

MS was used to confirm the early protein detection results obtained by analysis of 2D image analysis. The identify of differentially expressed proteins $(P<0.05$ and fold $>2)$ was established using MALDI TOF TOF MS.

Statistical Analysis, Clustering and Principal Component Analysis

The obtained results were statistically analyzed by $t$ test and SPSS (version 19) and $P<0.05$ was considered statistically significant.

Protein spots with $P<0.05$ were divided into 2 groups: increased and decreased protein expression groups. Then, clustering was used to identify the location of significantly significant spots, followed by PCA in determining the accuracy of the obtained results. Arithmetic cluster analysis was performed on two groups. Arithmetic cluster analysis employs correlation analysis to define if alterations in the levels of one individual protein are associated with alterations in the levels of a second protein across all samples (glioma and normal tissues). Arithmetic correlation algorithms are integral to the Progensis Same Spots software (Nonlinear Dynamics v 3.0, 2008). Multiple areas on correlation coefficients between protein features were calculated by Progenesis Same Spots and the information visually represented in the form of a dendrogram.

\section{Results}

\section{Separated Protein Spots Analysis}

Non-Linear Dynamics Progenesis Same Spot ${ }^{\circledR}$ software identified 243 spots (Figure 1A), from which 189 spots had $P<0.05$ that contained $78 \%$ of all the spots. From these 189 spots, 117 spots showed differential expressions more than 2 fold. These 117 spots constitute $72 \%$ of the spots with $P<0.05$ and $48 \%$ of the total spots. Differential

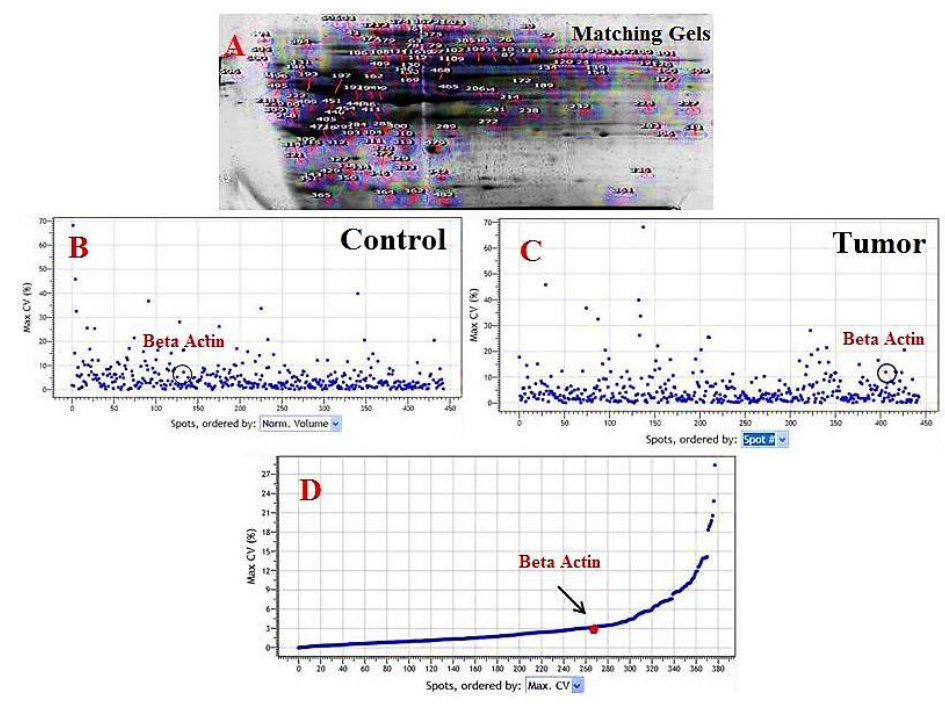

Figure 1. (A) Two-dimensional Gel Electrophoresis Image, (B) Beta Actin Proteins Position Alteration in Normal Glioma Tumor Tissue. (C) Changes of the Beta-Actin Protein Expression in Glioma Tumor Compared to Normal Tissue. 
fold expression of all the spots with $P<0.05$ are as follow: 79 spots with less than 2 fold ( $42 \%$ of the spots with $P<0.05$ and $33 \%$ of the total spots). Sixty-one spots with $2-4$ fold (32\% of the spots with $P<0.05$ and $25 \%$ of the total spots). Forty-nine spots with folds more than 4 (26\% of spots with $P<0.05$ and $20 \%$ of the total spots). Twelve spots corresponding to beta-actin were identified with elevated protein expression compared to normal tissue. These Twelve spots and their information are presented in Table 1. In Figure 1B and 1C, the position and position of beta-actin is shown on the gel (control and tumor). Also in Figure 1D, Increased expression of beta actin is shown in relation to the initial control.

Beta-Actin Protein Spot Confirmation by MALDITOF-TOF

Beta-actin protein spots were detected and confirmed by MALDI-TOF/TOF and the results are presented in Table 2.

Beta-Actin Protein Spot Confirmation by Clustering and Principal Component Analysis

As illustrated in Figure 2, spots located in the red and blue zone represent increased and decreased expression, respectively. Since the beta-actin spot in located in the red zone, it shows elevated protein expression. In order to continue to further understanding of rates of change, each of the tumors has been compared with the controls. Molecular weight and isoelectric $\mathrm{pH}$ values are recorded

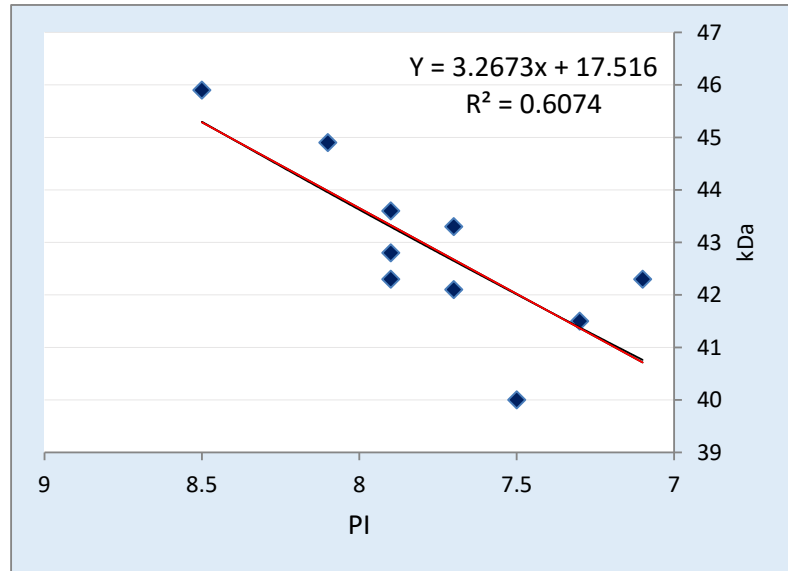

Figure 2. Diagram Scatter, Trandline Drawings for the Molecular Weight and Isoelectric pH, Based on Data From Table 1.

in Table 1, and the trend lines are shown in Figure 2. Afterwards, statistical analysis we have examined more closely, and it has been presented in Table 3 and Figure 3. PCA was also used to confirm the accuracy of clustering. PCA can be used to show that there are no variances in the data. PCA analysis results are presented in Figure 4.

\section{Discussion}

Since proteins are the cell's functional elements, studying their function and expression of transcription and even after their translation is important. ${ }^{13}$ Proteome

Table 1. Gel Electrophoresis Analysis and Information About Beta-Actin Protein Expression in Malignant Glioma Tumor Tissue

\begin{tabular}{|c|c|c|c|c|c|c|c|c|}
\hline & \multirow{2}{*}{ Tumor } & \multirow{2}{*}{ Grade } & \multirow{2}{*}{ Sex } & \multirow{2}{*}{ Age } & \multicolumn{4}{|c|}{ Beta Actin } \\
\hline & & & & & $P<0.05$ & Fold Change & PI & MW (kDa) \\
\hline Case 1 & Glioma-astrocytoma & III & Man & 44 & $2.234 \mathrm{e}-013$ & +2.7 & 7.7 & 42.1 \\
\hline Case 2 & Glioma-oligodendroglioma & III & Man & 49 & $2.038 \mathrm{e}-009$ & +2.2 & 7.9 & 42.3 \\
\hline Case 3 & Glioma-astrocytoma & III & Man & 66 & $3.329 \mathrm{e}-009$ & +3.1 & 8.1 & 44.9 \\
\hline Case 4 & Glioma-GBM & IV & Woman & 59 & $2.586 \mathrm{e}-009$ & +4.1 & 8.5 & 45.9 \\
\hline Case 5 & Glioma-astrocytoma & III & Man & 38 & $2.310 \mathrm{e}-009$ & +3.5 & 7.1 & 42.3 \\
\hline Case 6 & Glioma-astrocytoma & III & Woman & 51 & $4.407 \mathrm{e}-009$ & +2.2 & 7.5 & 40.0 \\
\hline Case 7 & Glioma-oligodendroglioma & III & Man & 47 & $2.182 \mathrm{e}-009$ & +2.1 & 7.9 & 42.8 \\
\hline Case 8 & Glioma-oligodendroglioma & III & Man & 63 & $5.968 \mathrm{e}-009$ & +2.5 & 7.7 & 43.3 \\
\hline Case 9 & Glioma-astrocytoma & III & Man & 69 & $3.253 e-011$ & +3.3 & 7.9 & 43.6 \\
\hline Case 10 & Glioma-astrocytoma & III & Woman & 59 & $1.876 \mathrm{e}-008$ & +2.3 & 7.3 & 41.5 \\
\hline Case 11 & Glioma-GBM & IV & Man & 56 & $2.942 \mathrm{e}-008$ & +3.6 & 7.4 & 44.4 \\
\hline Case 12 & Glioma-GBM & IV & Man & 60 & 7.806e-007 & +3.5 & 8.1 & 43.9 \\
\hline
\end{tabular}

Table 2. Beta Actin Protein Matching the Same Set of Peptides by Databank

\begin{tabular}{|c|c|c|c|c|c|c|}
\hline & Expressed Proteins Change & Fold Change & Number of Peptides & Score & Matches & Sequences Coverage \\
\hline Oligodendroglioma (III) & Up-Regulated & $2.1-2.5$ & 18 & 177 & $11 / 23$ & 33 \\
\hline Astrocytoma (III) & Up-Regulated & $2.3-3.5$ & 29 & 201 & $19 / 24$ & 21 \\
\hline Astrocytoma (IV) & Up-Regulated & $3.5-4.1$ & 21 & 189 & $18 / 20$ & 31 \\
\hline
\end{tabular}


Table 3. Statistical Analysis of Molecular Weight and Isoelectric pH for Beta Actin

\begin{tabular}{llllllllll}
\hline & Valid & Missing & Mean & Median & Error of Mean & Variance & Min & Max & Rande \\
\hline PI & 12 & 0 & 7.76 & 7.8 & 0.39 & 0.15 & 7.1 & 8.5 & 1.4 \\
MW & 12 & 0 & 43.08 & 43.05 & 1.60 & 2.57 & 40 & 45.9 & 5.9 \\
\hline
\end{tabular}

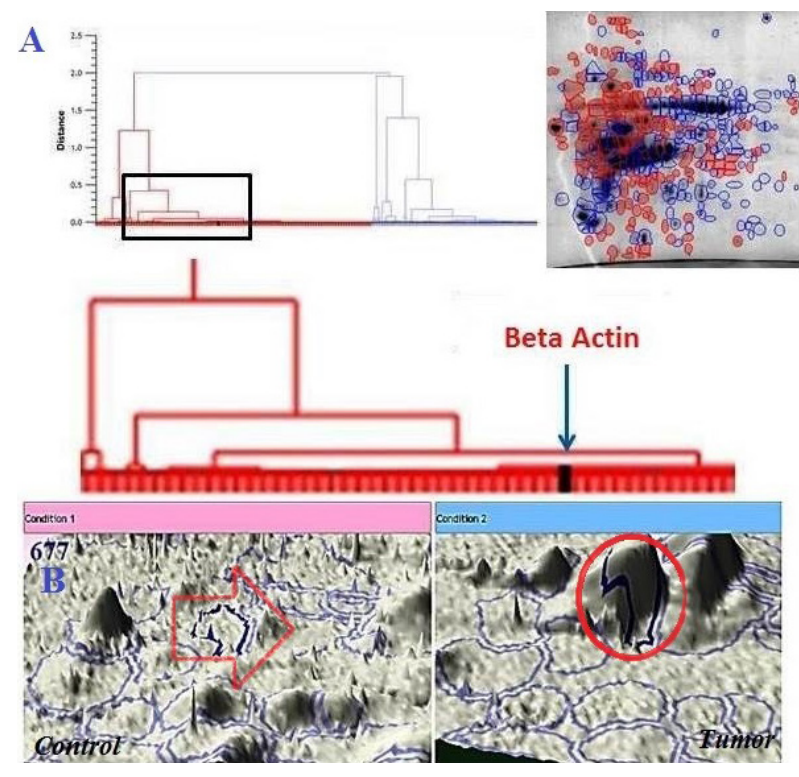

Figure 3. (A) Clustering the Proteins of Healthy and Tumor Sample Groups Based on Expression Changes. All these spots show significant expression changes in tumor tissue $(P<0.05$ and fold $>2)$. Red and blue zone represent increased and decreased expression, respectively. (B) 3D Images of Btaactin Protein.

(the whole protein content of a genome) is related to different diseases. Studying the proteome is critical in order to achieve a novel system based on proteins for disease prognosis, prevention and treatment. Cancer cells proteome analysis (including the study of biochemical and biophysical properties of proteomic profiles) which enables us to determine the role of different proteins in cancer initiation. ${ }^{14,15}$

Proteomics studies are performed towards different goals including functional studies and finding novel protein biomarkers for rapid diagnosis. This study was performed with the aim of finding possible protein biomarkers for early glioma tumor detection. ${ }^{16,17}$ Our results showed elevated expression levels of beta-actin in malignant glioma tumors. Beta-actin is a very common skeletal protein that is present almost everywhere in the cell and is involved in cellular movements. Beta-actin's role in cellular movements affects other cellular functions as well including cell division, immune response and cellular transformation. ${ }^{18-21}$ Based on beta-actin's importance in cell function, proteomics investigations can be useful in better understanding and finding a biomarker candidate for malignant glioma. It is important to know when a cell is transformed and when it becomes malignant. ${ }^{22,23}$ Here we evaluated the beta-actin expression in malignant cells. Our results indicate that beta-actin expression control is controlled intracellularly since its expression levels differ with cell type and situation. Previous studies have indicated that tumor cell's malignancy is related to actin polymers. Despite no standard has been determined yet, all types of tumor cells show common cellular movements involving beta-actin protein. ${ }^{24}$
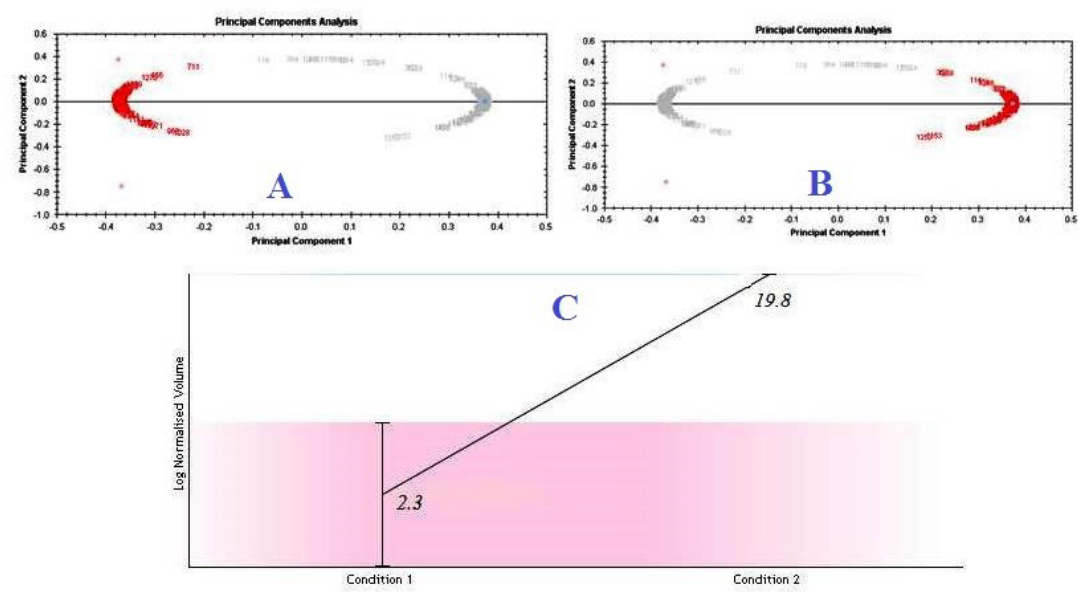

Figure 4. (A) Principal Component Analysis of Proteins From Healthy and Tumor Tissue Based on Expression Levels. All these spots show significant expression changes in tumor tissue $(P<0.05$ and fold $>2)$. (A) Elevated expression compared to healthy tissue and (B) lower expression in tumor compared to healthy tissue. (C) For example: Beta actin protein has an up-regulation about 4.1 (fold = 4.1) in glioma-GBM (IV) brain tumors than normal brain tissue. 
Nebl and colleagues studies on beta-actin showed that cell's skeletal proteins including actin fibers affect lipid rafts in the cell membrane. Lipid rafts play an important role in the membranes fluidity which in turn affects cellular pathogenicity. ${ }^{25,26}$

Proteomics analysis has identified several proteins involved in oxidative stress response. Beta-actin is an abundant important protein in the glutathionylation process following oxidative stress. The first cellular response results in superoxide generation which can eventually results in cellular transformation. ${ }^{27-30}$

A cell needs to undergo specific structural changes in order to become malignant. Increase in beta-actin levels is related to invasiveness, including its effects on the carcinogen, primary and secondary GBM. ${ }^{31,32}$ In this situation, beta-actin polymerization results in an invasive structure which affects cellular movements and can lead to invasiveness and malignancy. ${ }^{33,34}$

There are a large number of studies in the literature on beta-actin's role in different types of cancer and gliomas, including the studies of Fages et al, Ziv-Av et al and Panopoulos and colleagues which are all confirm our results on the effect of increased beta-actin expression in different types of cancer including glioma. However, different folding is reported by these groups and us. ${ }^{35-37}$

\section{Conflict of Interest Disclosures}

The authors declare that they have no conflict of interests.

Ethical Statement

All patients gave informed consent before participating in this study. The research was approved by the ethics committee of Islamic Azad university.

Funding and Support

This research was funded by Islamic Azad University, Iran.

\section{References}

1. Hashemi M, Pooladi M, Khaghani-Razi-Abad S. The investigation of changes in proteins expression (Apolipoprotein A1 and albumin) in malignant astrocytoma brain tumor. J Cancer Res Ther. 2014;10(1):107-11. doi: 10.4103/09731482.131413.

2. Gollapalli K, Ray S, Srivastava R, Renu D, Singh P, Dhali S, et al. Investigation of serum proteome alterations in human glioblastoma multiforme. Proteomics. 2012;12(14): 2378-90. doi: 10.1002/pmic.201200002.

3. Lemée JM, Com E, Clavreul A, Avril T, Quillien V, de Tayrac $\mathrm{M}$, et al. Proteomic analysis of glioblastomas: what is the best brain control sample? J Proteomics. 2013; 85:165-73. doi: 10.1016/j.jprot.2013.04.031

4. Pooladi M, Khaghani-Razi-Abad S, Hashemi M. Proteomics analysis of human brain glial cell astrocytoma proteome by 2D gel. Indian J Cancer. 2014;51(2):159-162.

5. Jansen M, Yip S, Louis DN. Molecular pathology in adult gliomas: diagnostic, prognostic, and predictive markers. Lancet Neurol. 2010; 9(7):717-26. doi: 10.1016/S14744422(10)70105-8.

6. Pooladi M, Khaghani-Razi-Abad S, Nazarian N, FirouziDalvand L, Hooshiyar M. Altered expression of Isocitrate
Dehydrogenases1 in astrocytoma (III and IV) and oligodendroglioma (III) brain tumors. Journal of Protein and Proteomics. 2014;5(1): 55-64.

7. Figarella-Branger D, Bouvier C. Histological classification of human gliomas: state of art and controversies. Bull Cancer. 2005;92(4):301-9

8. Saratsis AM, Yadavilli S, Magge S, Rood BR, Perez J, Hill DA, et al. Insights into pediatric diffuse intrinsic pontine glioma through proteomic analysis of cerebrospinal fluid. Neuro Oncol. 2012;14(5):547-60. doi: 10.1093/neuonc/nos067.

9. Honda K, Ono M, Shitashige M, Masuda M, Kamita M, Miura $\mathrm{N}$, et al. Proteomic approaches to the discovery of cancer biomarkers for early detection and personalized medicine. Jpn J Clin Oncol. 2013; 43(2):103-9. doi: 10.1093/jjco/hys200.

10. Khaghani-Razi-Abad S, Hashemi M, Pooladi M, Entezari M, Kazemi E. Proteomics analysis of human brain glial cell oligodandroglioma proteome by 2D gel. Gene. 2015;569; 77 82. doi: 10.1016/j.gene.2015.05.039.

11. Fang X, Wang C, Balgley BM, Zhao K, Wang W, He F, et al. Targeted tissue proteomic analysis of human astrocytomas. J Proteome Res. 2012;11(8):3937-46. doi: 10.1021/pr300303t.

12. Cao H, Wang F, Li XJ. Future Strategies on Glioma Research: From Big Data to the Clinic. Genomics Proteomics Bioinformatics. 2017;15(4):263-265. doi: 10.1016/j. gpb.2017.07.001

13. Ardekani AM, Akhondi MM, Sadeghi MR. Application of genomic and proteomic technologies to early detection of cancer. Arch Iran Med. 2008; 11(4):427-34. doi: 08114/ AIM.0015.

14. Pooladi M, Rezaei-Tavirani M, Hashemi M, Hesami-Tackallou S, Khaghani-Razi-Abad S, Moradi A, et al. Cluster and Principal Component Analysis of Human Glioblastoma Multiforme (GBM) Tumor Proteome. Iran J Cancer Prev. 2014;7(2):87-95.

15. Meunier B, Bouley J, Piec I, Bernard C, Picard B, Hocquette JF. Data analysis methods for detection of differential protein expression in two-dimensional gel electrophoresis. Anal Biochem. 2005; 340(2):226-30. doi: 10.1016/j. ab.2005.02.028.

16. Vogel TW, Zhuang Z, Li J, Okamoto H, Furuta M, Lee YS, et al. Proteins and protein pattern differences between glioma cell lines and glioblastoma multiforme. Clin Cancer Res. 2005;11(10): 3624-32.

17. Boja ES, Rodriguez $\mathrm{H}$. The path to clinical proteomics research: integration of proteomics, genomics, clinical laboratory and regulatory science. Korean J Lab Med. 2011;31(2):61-71. doi: 10.3343/kjlm.2011.31.2.61.

18. Tondeleir D, Lambrechts A, Müller M, Jonckheere V, Doll $\mathrm{T}$, Vandamme $\mathrm{D}$, et al. Cells lacking $\beta$-actin are genetically reprogrammed and maintain conditional migratory capacity. Mol Cell Proteomics. 2012; 11(8):255-71. doi: 10.1074/mcp. M111.015099.

19. Dubey M, Singh AK, Awasthi D, Nagarkoti S, Kumar S, Ali W, et al. L-plastin S-glutathionylation promotes reduced binding to $\beta$-actin and affects neutrophil functions. Free Radic Biol Med. 2015;86:1-15. doi: 10.1016/j.freeradbiomed.2015.04.008. Kalo A, Kanter I, Shraga A, Sheinberger J, Tzemach H, Kinor $N$, et al. Cellular Levels of Signaling Factors Are Sensed by $\beta$-actin Alleles to Modulate Transcriptional Pulse Intensity. Cell Rep. 2015; 11(3):419-32. doi: 10.1016/j.celrep.2015.03.039.

20. Kalo A, Kanter I, Shraga A, Sheinberger J, Tzemach H, Kinor $\mathrm{N}$, et al. Cellular Levels of Signaling Factors Are Sensed by $\beta$-actin Alleles to Modulate Transcriptional Pulse Intensity. Cell Rep. 2015;11(3):419-32. doi: 10.1016/j.celrep.2015.10.053.

21. Lichti CF, Mostovenko E, Wadsworth PA, Lynch GC, Pettitt BM, Sulman EP, et al. Systematic identification of single amino acid variants in glioma stem-cell-derived chromosome 19 
proteins. J Proteome Res. 2015;14(2):778-86. doi: 10.1021/ pr500810g.

22. Khalil AA. Biomarker discovery: a proteomic approach for brain cancer profiling. Cancer Sci. 2007; 98(2):201-13.

23. Bi B, Li F, Guo J, Li C, Jing R, Lv X, et al. Label-free quantitative proteomics unravels the importance of RNA processing in glioma malignancy. Neuroscience. 2017;351:84-95. doi: 10.1016/j.neuroscience.2017.03.023

24. Westhoff CC, Schoner K, Hartmann S, Sesterhenn AM, Moll R. Actin isoform expression patterns in adult extracardiac and cardiac rhabdomyomas indicate a different cell of origin. Virchows Arch. 2017; 470(3):285-290. doi: 10.1007/s00428017-2069-3

25. Nebl T, Pestonjamasp KN, Leszyk JD, Crowley JL, Oh SW, Luna EJ. Proteomic analysis of a detergent-resistant membrane skeleton from neutrophil plasma membranes. J Biol Chem. 2002;277(45):43399-409. doi:10.1074/jbc.M205386200.

26. Cherepanova O, Orlova A, Galkin VE, van der Ven PF, Fürst $\mathrm{DO}$, Jin JP, et al. Xin-repeats and nebulin-like repeats bind to F-actin in a similar manner. J Mol Biol. 2006 24;356(3):71423.

27. Tomanek L. Proteomics to study adaptations in marine organisms to environmental stress. J Proteomics. 2014; 105:92-106.

28. Ostrowska Z, Moraczewska J. Cofilin - a protein controlling dynamics of actin filaments. Postepy Hig Med Dosw (Online). 2017;71(0):339-351.

29. Poschmann G, Grzendowski M, Stefanski A, Bruns E, Meyer $\mathrm{HE}$, Stühler K. Redox proteomics reveal stress responsive proteins linking peroxiredoxin-1 status in glioma to chemosensitivity and oxidative stress. Biochim Biophys Acta.
2015;1854(6):624-31.

30. Nowak D, Krawczenko A, Dus D, Malicka-Blaszkiewicz M. Actin in human colon adenocarcinoma cells with different metastatic potential. Acta Biochim Pol. 2002;49:823-828.

31. He J, Liu Y, Lubman DM. Targeting glioblastoma stem cells: cell surface markers. Curr Med Chem. 2012;19(35):6050-5. doi: 10.2174/0929867311209066050.

32. Jovčevska I, Zupanec N, Kočevar N, Cesselli D, Podergajs $\mathrm{N}$, Stokin $\mathrm{CL}$, et al. TRIM28 and $\beta$-actin identified via nanobody-based reverse proteomics approach as possible human glioblastoma biomarkers. PLoS One. 2014 24;9(11): e113688. doi: 10.1371/journal.pone.0113688.

33. Boczkowska M, Yurtsever Z, Rebowski G, Eck MJ, Dominguez R. Crystal Structure of Leiomodin 2 in Complex with Actin: A Structural and Functional Reexamination. Biophys J. 2017;113(4):889-899. doi: 10.1016/j.bpj.2017.07.007.

34. Lee W, Lim S, Kim Y. The role of myosin II in glioma invasion: A mathematical model. PLoS One. 2017;12(2):e0171312. doi: 10.1371/journal.pone.0171312.

35. Fages $\mathrm{C}$, Kaksonen $\mathrm{M}$, Kinnunen $\mathrm{T}$, Punnonen EL, Rauvala $\mathrm{H}$. Molecule with the cell surface localizes beta-actin mRNA. J Cell Sci. 1998;111( Pt 20):3073-80.

36. Panopoulos A, Howell M, Fotedar R, Margolis RL. Glioblastoma motility occurs in the absence of actin polymer. Mol Biol Cell. 2011;22(13):2212-20. doi: 10.1091/mbc.E1010-0849.

37. Ziv-Av A, Giladi ND, Lee HK, Cazacu S, Finniss S, Xiang C, et al. RTVP-1 regulates glioma cell migration and invasion via interaction with N-WASP and hnRNPK. Oncotarget. 2015 14;6(23):19826-40. doi:10.18632/oncotarget.4471. 